\title{
Potential Legal Issues and Care Implications during Care-Prevention Gymnastic Exercises for the Elderly Using Pepper in Long Term Health Care Facilities
}

\author{
Ryuichi Tanioka1, Rozzano Locsin², Yuko Yasuhara², Tetsuya Tanioka² \\ ${ }^{1}$ Graduate School of Policy Studies Student, Tokushima Bunri University, Tokushima, Japan \\ ${ }^{2}$ Department of Nursing, Institute of Biomedical Sciences, Tokushima University, Tokushima, Japan \\ Email: taniokaryuichi@gmail.com
}

How to cite this paper: Tanioka, R., Locsin, R., Yasuhara, Y. and Tanioka, T. (2018) Potential Legal Issues and Care Implications during Care-Prevention Gymnastic Exercises for the Elderly Using Pepper in Long Term Health Care Facilities. Intelligent Control and Automation, 9, 85-93. https://doi.org/10.4236/ica.2018.93007

Received: May 15, 2018

Accepted: August 21, 2018

Published: August 24, 2018

Copyright $\odot 2018$ by authors and Scientific Research Publishing Inc. This work is licensed under the Creative Commons Attribution International License (CC BY 4.0).

http://creativecommons.org/licenses/by/4.0/

\begin{abstract}
In Japan, the shortage of personnel is a problem in long-term care nursing and rehabilitative care prevention. Nevertheless, Japan has taken measures to compensate for these shortages by promoting medical and nursing care activities using robotic technologies, and employing human resources from overseas. The purpose of this study was to determine potential legal issues and subsequent implications for care during prevention gymnastic exercises for the elderly using Pepper in long-term health facilities. The application program of Care-Prevention Gymnastics Exercises for Pepper (Pepper with CPGE) was made by the Xing Company Japan. Currently, care workers become intermediaries for the safe use of Pepper with CPGE. However, it was realized that some legal issues may arise if Pepper with CPGE alone will carry out these preventive care programs for the elderly without the presence of care workers as intermediaries. In this situation, using Pepper with CPGE alone to conduct care prevention gymnastics will require safety measures to prevent these possible practice issues and anticipate implications for care. In this regard, determining detailed target levels of rehabilitation exercise demands and environmental setting safety become essential factors. The use of humanoid robots in healthcare is expected to influence more practice protocols in contemporary and futurist rehabilitative human care. The identification of possible safety issues in performance and environmental situations, and implications for care are critical to ensure safe and valuable rehabilitative health care practices for the elderly population.
\end{abstract}

\section{Keywords}

Potential Legal Issues, Care-Prevention Gymnastic Exercises, Elderly, Pepper, 
Long-Term Health Facilities, Application Program

\section{Introduction}

In Japan, the shortage of personnel is a problem in long-term care nursing and in rehabilitative care. However, Japan has taken measures to compensate for these shortages by promoting medical and nursing care activities using robotic technologies and employing human resources from overseas.

As of 2016, the population in Japan was approximately 126.93 million, among whom are the elderly population aged 65 years and over which was approximately 34.59 million, about $27.3 \%$ (proportion of elderly people) of the total population [1]. According to the cabinet office [1], the total population in Japan is predicted to decrease and is estimated to be 120 million in 2029, 99.24 million in 2053 , and 88.08 million in 2065 . However, the elderly population will continue to increase and is estimated to reach 36.77 million in 2042. With the continuing reduction in total population and increase in elderly population, the proportion of elderly population will be $33.3 \%$ in 2036 . It is predicted to increase even after that and is estimated to reach $38.4 \%$ in 2065.

As the elderly population increases, shortage of medical (healthcare) personnel has become a significant problem. As of 2012, the total number of long-term care nursing personnel was estimated to be 1.49 million [2], an estimated demand of 2.53 million long-term care nursing personnel in 2025, and an estimated supply of 2.15 million of long-term care nursing personnel. Under the current trend scenario, the estimated gap between supply and demand is approximately 0.38 million [3].

In response to these identified needs and demands, it is realized that technical capabilities of healthcare robots will be dramatically needed, and evolving consistently to meet these needs [4] [5] [6] [7]. Some studies have been conducted which focused on topics of healthcare robot development, including ethico-moral dilemmas in health care [8] [9]. Today, the role functions of these robots as intermediaries were shown to be of high versatility, indicating that health care situations such as those demanded by elderly persons can be performed by other healthcare providers such as by human physiotherapists [10].

However today, healthcare workers have become intermediaries for the safe use of the application program of Care Prevention Gymnastics Exercises for Pepper (Pepper with CPGE). It is therefore concerning that some legal issues may arise if Pepper with CPGE alone will carry out these preventive care programs for the elderly, that is, without the presence of human care workers as intermediaries. Using Pepper with CPGE alone to conduct care prevention gymnastics will require safety measures to prevent possible practice issues, and anticipate implications for care.

The development of medical robots is rapidly and steadily growing. However, 
it is important to examine not only the convenience of robot introduction but also the limitations of the scope of function that these robots can independently do, particularly the possible dangers, and problems (insurance scores, laws, etc.) concerning their introduction.

Determining detailed target levels of rehabilitation exercise demands and environmental setting safety become essential factors. In introducing Pepper with CPGE to provide elderly care in the psychiatric hospital or health care facility units for the elderly, it is essential to consider legal responsibilities, especially for the possibilities of accidents involving physico-physiological activities.

\section{Purpose}

The purpose of this study was to determine potential legal issues and describe subsequent implications for care during preventive gymnastics exercises for the elderly using Pepper with CPGE in long-term health care facilities.

\section{Explanation on Pepper}

\subsection{What Is Pepper?}

Standard specification of Pepper is as a humanoid robot manufactured by SoftBank Robotics (formerly Aldebaran Robotics), which is owned by SoftBank [11] [12]. It is designed with the ability to "read" signs and symptoms reflecting emotions. It was introduced in a conference on June 5, 2014. The robot's head has four microphones, two HD cameras (in the mouth and forehead), and a 3-D depth sensor (behind the eyes). There is a gyroscope in the torso and touch sensors at its head and hands. There is some possibility that Pepper has a mechanism that can avoid danger of accidental contact with others as it swings its upper limbs. The movable base has two sonars, six lasers, three bumper sensors, and a gyroscope. Pepper using applications has been used in banks, restaurants, and medical facilities in Japan. In addition, with the latest model of the Pepper, it has an improved and richer conversation pattern and can store memory of faces and names of persons with a face authentication system. The Pepper is equipped with an Emergency Stop Button. There should be no obstacles within a range of 2 meters (6 feet) in front of Pepper, as it could be recognized as a human and may not be avoided.

\subsection{Application Program of Care Prevention Gymnastics Exercises for Pepper [13]}

The application program of Care Prevention Gymnastics Exercises for Pepper was made by Xing Company Japan. The concept of this application is for elderly users to enjoy entertaining activities without them getting bored. Reducing the burden on medical staff (Pepper will do everything from the beginning of recreation to the end) is another feature mas the medical staff do not have to think about difficult operations or ways of recreation.

It has a body-brain gymnastics recreation program lasting 40 minutes dura- 
tion, and tailored to the level of desired physical activities. This consists of moving, watching/healing, and playing to the "Move the body" activity, perform gymnastics, and other such types of music. The elderly can also see old-fashioned news videos on the "Watching/Healing" monitor of Pepper. In "Playing", a brain gymnastic activity such as a quiz is featured. Pepper facilitates and interlocks with the video displayed on the TV monitor-with progression of activities in accordance with programmed activities. At the present time, safety and efficacy is secured by human caretakers with CPGE-assisted medical personnel as intermediaries. Today, Pepper with CPGE cannot move or respond to all patients and users yet.

\section{Relationship among Medical Laws/Related Laws and Humanoid Robots in Japan}

\subsection{Description of Humanoid Robots in Japanese Laws and Regulations}

"Medical Care Act, Medical Practitioners' Act", "Act on Public Health Nurses, Midwives, and Nurses", "Physical Therapists and Occupational Therapists Act", "Certified Social Worker and Certified Care Worker Act" do not describe or explain the governing terms for the humanoid robot and other healthcare robots. On the other hand, the Ordinance on Industrial Safety and Health, article (36) item (32) describes laws for industrial robot. Similarly, Radio law enforcement regulation, article (2), paragraph (1), item (43) describes terms for Meteorological Radio Robots.

The following Law on Securing Quality, Efficacy and Safety of Products including Pharmaceuticals and Medical devices, article (2), paragraph (4) stipulate, that "the term 'medical device' as used in this Law refers to medical appliances or instruments (excluding regenerative medicine products) intended for use in the diagnosis, treatment or prevention of disease in humans or animals, or intended to affect the structure and functions of the bodies of humans or animals, as specified by Cabinet Order." However, it is thought that related ordinances do describe what a humanoid robot or healthcare robot is. It is therefore necessary to urgently consider the roles and functions of "humanoid robots" in the medical and nursing care situations and settings of care, including the purposes that these humanoid robots can serve.

\subsection{Consideration when a Humanoid Robot Causes a Medical Accident}

According to the Civil Code of Japan, only natural persons and legal persons are afforded rights and obligations [14]. The Civil Code, article (3), paragraph (1) specifies the following regulations, "the enjoyment of private rights shall commence at birth". Additionally, Civil Code, article (43) states that "A juridical person shall have rights and assume duties to the extent of the purpose provided in the applicable articles of incorporation or act of endowment subject to the ap- 
plicable provisions of the laws and regulations". Who will bear the responsibility for injuries and accidents cause by humanoid robots in the elderly care unit, in the psychiatric hospital, or other health care facility?

\subsection{Predictable Injury Accidents of the Elderly when Pepper Alone, Carries Out the Care Prevention Gymnastics Exercises for the Elderly}

Falls and injuries of users from collisions with Pepper may cause sudden change of user's conditions. Product Liability Act, article (1) [15] has listed that "the purpose of this Act is to protect the victim of the injury to life, body, or property which is caused by a defect in the product by setting forth liability of the manufacturer, etc. for damages, and thereby to contribute to the stabilization and improvement of the life of the citizens and to the sound development of the national economy." Also, article (2) paragraph (2) has listed "the term 'defect' as used in this Act shall mean a lack of safety that the product ordinarily should provide, taking into account the nature of the product, the ordinarily foreseeable manner of use of the product, the time when the manufacturer, etc. delivered the product, and other circumstances concerning the product." Moreover, paragraph (3) has listed 'The term 'manufacturer, etc.' as used in this Act shall mean the following: (i) any person who manufactured, processed, or imported the product in the course of trade (is hereinafter referred to as 'manufacturer')."

Therefore, if a medical accident occurs with the elderly while doing Care Prevention Gymnastics Exercises by Pepper alone, based on the Product Liability Act, there is a possibility that the manufacturer of Pepper or the application developer installed on Pepper may be charged with the responsibility. Product liability law, article (3) has listed "The manufacturer, etc. shall be liable for damages arising from the infringement of life, body or property of others which is caused by the defect in the delivered product which was manufactured, processed, imported, or provided with the representation of name, etc. described in item 2 or item 3 of paragraph 3 of the preceding Article, provided, however, that the manufacturer, etc. shall not be liable when the damages occur only with respect to such product." There is a possibility that the developer who developed Pepper may be responsible in the case of falling and injuring the elderly because of Pepper's movement.

Another legal precedent is the Civil Code, article (709) [16] which states that "A person who has intentionally or negligently infringed any right of others, or legally protected interest of others, shall be liable to compensate any damages resulting in consequence." Negligence is interpreted as lack of care, or violation of the duty of care, and "violation of the duty of care" refers to the fact that the results could not be avoided due to the inability to fulfill foreseeable obligations because of lack of care, where the results were foreseeable if utmost care were exercised (foreseeability), which could have avoided the development of the results (avoidability) [17].” 
Regarding confirming patient's physical condition, managing risk, and performing Care Prevention Gymnastics Exercises (CPGE), the case of negligence with respect to setup and measures concerning environment preparation including mutual perception of distance between patients and removal of obstacles, a possibility that the facility manager may be charged with responsibility from the perspectives of foreseeability and avoidability" may occur.

\section{Consideration of Robot Safety Standards and Actual Accidents}

\subsection{About Safety Standards of Robots}

International Organization for Standardization (ISO) has published 22,119 International Standards and related documents, covering almost every industry, from technology, to food safety, to agriculture and healthcare [18]. ISO 13482:2014 specifies requirements and guidelines for the inherently safe design, protective measures, and information for use of personal care robots. In particular the following three types of personal care robots [19]: mobile servant robot; physical assistant robot; and person carrier robot. ISO 13482:2014 does not apply to [15]: robots travelling faster than $20 \mathrm{~km} / \mathrm{h}$; robot toys; water-borne robots and flying robots; industrial robots are covered in ISO 10218, as well as robots as medical devices; and military or public force application robots. The scope of ISO 13482:2014 is limited primarily to human care related hazards but, where appropriate, it includes domestic animals or property (defined as safety-related objects), when the personal care robot is properly installed and maintained and used for its intended purpose or under conditions which can reasonably be foreseen [15].

However, the Japanese Industrial Standards (JIS) specifies the standard use for industrial activities. Japanese Industrial Standards Committee is composed of many nationwide committees and plays vital roles in standardizing activities [20]. "JIS B 8445: Robots and robotic devices-Safety requirements for personal care robots" and the "JIS B 8446-1: Safety requirements for personal care robots-Part 1: Static stable mobile servant robot with no manipulator"-are JIS safety standards for personal care robots issued on April 20, 2016. "JIS B 8445" is the Japanese translation of the International Standards Organization's "ISO 13482 Robots and robotic devices-Safety requirement for personal care robots." And "JIS B 8446" is comprised of 3 types of standards Japan has taken the initiative to establish based on the ISO 13482 [21] [22].

\subsection{Accidents when Actually Using Robots}

\subsubsection{A Case of Remote Surgery Using Da Vinci Surgical System [23]}

On September 8, 2010, a medical accident occurred in surgery using the da Vinci Surgical System at a medical facility in Japan. The accident damaged the pancreas during surgery for gastric cancer and the patient had complications of acute pancreatitis after surgery. From these complications arose non-occlusive 
mesenteric ischemia and necrotizing fasciitis. Reoperation was performed, however, patient died on 5th postoperative day with multiple organ failure.

The accident report states as follows: "Although there was no problem in selecting the operation, apparently informed consent was not obtained appropriately, and with respect to involvement of the team in the first case to the fourth, veteran physicians were not invited even once, suggesting problems with the history of performing operations independently." "It was confirmed from the video recording of the operation that the pancreas was kept strongly pressed for about six minutes by the robotic forceps from the ventral side towards the dorsal side to secure the operative field, and judging from the relative anatomical locations, it is presumed that the pancreas was squeezed between the robotic forceps and the vertebra. Damage to the pancreas may have occurred due to failure concerning strict observance of two important elements of "protecting the pancreas" and "fully understanding the characteristics of the equipment used" and cannot be attributed to the da Vinci Surgical System as such."

\subsubsection{Learning from Death Accidents of Industrial Robots}

During the period from 2000 to 2009, in Japan, 23 people died due to occupational accidents by industrial robots [24]. Twenty of them were due to fatal crushing (sandwiched) by robots. This resulted in the Labor Safety and Health Regulations stipulation to isolate people and robots using some form of fencing etc. during automatic operations. However, most of these accidents occur within the vicinity of movable robot parts and within the range of the industrial robot when in operation. It is necessary, therefore, to verify safety applications particularly when planning the use of Pepper and the Care Prevention Gymnastics Exercises. In case of negligence in the verification process and an accident occurs, there is a greater possibility of being charged with irresponsibility from a foreseeability perspective. Accordingly, it is necessary to take safety precautions by confirming the safety of the application prior to its use by elderly patients.

Moreover, in introducing Pepper in facilities with the purpose of Care Prevention Gymnastics Exercises, it is very important to establish a committee that can deliberate regularly on anticipated accidents and environmental setup, on methods for selecting target patients, on method of securing safety and device appropriate measures and implementation of detailed revisions. At the same time, it is also deemed necessary that the facility staff improve their understanding about Pepper and its applications, and that it be documented that staff be thoroughly conversant with the dangerous situations that may result in accidents.

\section{Conclusions}

The use of humanoid robots in healthcare is expected to influence more practice protocols in contemporary and futurist rehabilitative human care. The identification of possible safety issues in performance and environmental situations and implications for care are critical to ensure safe and valuable rehabilitative health 
care practices for the elderly population. This is particularly important in the Japanese health care settings.

Pepper's introduction to medical and welfare facilities is progressing in Japan. Little is known about whether there is a legal problem. If there is a legal problem, further examination is needed as to whether to use as it is. However, if we are too careful with the introduction of Pepper, there is a possibility that even if we know that it is convenient we can break the spread. Therefore, it is necessary to ensure that there is proper research and legislation in place to limit undue liability on the part of the medical site to a reasonable risk level.

Also, since a robot is a machine, regular maintenance, misoperation, power down, etc. must also be considered. When Pepper progresses in the future, and the amount of activities and the range of activities widen, there could be recognition of additional concerns and potentially dangerous scenarios.

\section{Acknowledgements}

This work was supported by JSPS KAKENHI Grant Number JP17H01609.

\section{References}

[1] Cabinet Office, Government of Japan (2016) Annual Report on the Aging Society: 2016 (Summary). http://www8.cao.go.jp/kourei/english/annualreport/2016/2016pdf_e.html

[2] Ministry of Health, Labour and Welfare (2017) Employment Measures for Nursing-Care Staff. (In Japanese)

http://www.mhlw.go.jp/file/05-Shingikai-12601000-Seisakutoukatsukan-Sanjikanshi tsu_Shakaihoshoutantou/0000175117.pdf

[3] Ministry of Health, Labour and Welfare (2015) On Supply Demand Estimate (Fixed Value) for Care Workers for 2025. http://www.mhlw.go.jp/stf/houdou/0000088998.html

[4] Nativio, D.G. (2000) Robots and Nurses. Nursing Outlook, 48, 154-155.

[5] Huschilt, J. and Clune, L. (2012) The Use of Socially Assistive Robots for Dementia Care. Journal of Gerontological Nursing, 38, 15-19.

[6] Sharts-Hopko, N.C. (2014) The Coming Revolution in Personal Care Robotics: What Does It Mean for Nurses? Nursing Administration Quarterly, 38, 5-12.

[7] Walter, E. (2017) Replacing the Human Touch. Nursing Standard, 31, 30.

[8] Sharkey, A. and Sharkey, N. (2012) Granny and the Robots: Ethical Issues in Robot Care for the Elderly. Ethics and Information Technology, 14, 27-40.

[9] Metzler, T.A., Lewis, L.M. and Pope, L.C. (2016) Could Robots Become Authentic Companions in Nursing Care? Nursing Philosophy, 17, 36-48.

[10] Gerling, K., Hebesberger, D., Dondrup, C., Körtner, T. and Hanheide, M. (2016) Robot Deployment in Long-Term Care: Case Study on Using a Mobile Robot to Support Physiotherapy. Zeitschrift für Gerontologie und Geriatrie, 49, 288-297.

[11] Softbank (2017) Pepper for Biz. (In Japanese) https://www.softbank.jp/robot/biz/

[12] WIKIPEDIA (2018) Pepper (Robot). https://en.wikipedia.org/wiki/Pepper_(robot)

[13] XING Inc. (2016) Kenko Ookokufor Pepper. (In Japanese) https://roboapp.joysound.com/ 
[14] Nambu, T. (2016) Legal Regulations and Public Policies for Next-Generation Robots in Japan. AI \& Society, 31, 483-500.

https://link.springer.com/article/10.1007\%2Fs00146-015-0628-1

[15] Ministry of Justice, Japan (2018) Japanese Law Translation, Product Liability Act. http://www.japaneselawtranslation.go.jp/law/detail/?id=86\&vm $=04 \& \mathrm{re}=02$

[16] Ministry of Justice, Japan (2018) Japanese Law Translation, Civil Code (Part I, Part II, and Part III). http://www.japaneselawtranslation.go.jp/law/detail/?id=2057\&vm=\&re

[17] Takahashi, Y. (2005) Hajimete manabu keihou: Kaisei keihou kannzen taiou. Sanshusha Publishing Co. Ltd., 56-57. (In Japanese)

[18] International Organization for Standardization. About ISO. https://www.iso.org/about-us.html

[19] International Organization for Standardization (2014) ISO 13482:2014. https://www.iso.org/standard/53820.html

[20] Japanese Industrial Standards Committee (2017) Japanese Industrial Standards Committee, Industrial Standardization and JIS. (In Japanese) http://www.jisc.go.jp/jis-act/index.html

[21] Cyberdyne Inc. (2015) The Japanese Industrial Standards Committee's Subcommittee Approved the Establishment of the Japanese Industrial Standards (JIS) for Personal Care Robots. Following the Course of International Safety Standards, CYBERDYNE Is Leading the Development of National Standards.

https://www.cyberdyne.jp/english/company/PressReleases_detail.html?id=3833

[22] The Free Library (2016) Japan: Panasonic's Autonomous Delivery Robot-HOSPI(R) - Receives the International Safety Standard ISO 13482 as well as the First Certification under the New JIS Safety Standards.

https://www.thefreelibrary.com/Japan+\%3A+Panasonic\%27s+Autonomous+Delive ry+Robot+-+HOSPI(R)+-+Receives...-a0450776926

[23] Nagoya University Hospital. Medical Accident Investigation Board (2011) Accident Investigation Report. (In Japanese)

https://www.med.nagoya-u.ac.jp/hospital/departments/file/authoralfe4/2017/pdf/2 0110607houkokusyo.pdf

[24] Hoshi, T., Ikeda, H., Okabe, K. and Saito, T. (2012) Proposal of Revision of Regulations Based on Labour Accident Analysis and Questionnaire on Industrial Robots. Journal of Occupational Safety and Health, 5, 3-15. (In Japanese) https://doi.org/10.2486/josh.5.3 